\title{
Spondylometaphyseal dysplasia, Golden type
}

INSERM

\section{Source}

INSERM. (1999). Orphanet: an online rare disease and orphan drug data base. Spondylometaphyseal dysplasia, Golden type. ORPHA:168544

Spondylometaphyseal dysplasia, Golden type is a rare primary bone dysplasia disorder characterized by severe short stature, coarse facies, thoracolumbar kyphoscoliosis and enlarged joints with contractures. Psychomotor delay and intellectual disability may also be associated. Radiographic features include flat vertebral bodies, lacy ossification of the metaphyses of long bones and iliac crests, and marked sclerosis of the skull base. 